\title{
Grey Ontology Model for Expert Knowledge Representation
}

\author{
Bin Shen and Shuyu Zhao* \\ Caoan Road 4800, Shanghai 201804, China \\ *Corresponding author
}

\begin{abstract}
In order to improve the knowledge representation of ontology for dealing with grey uncertainty, grey ontology is proposed. Firstly, grey systems theory, probability theory and fuzzy theory are compared. Secondly, interval grey number and its calculation are introduced. At last, the model grey ontology is proposed and the main elements are also analyzed. It shows that grey ontology can overcome the limitation of other ontologies to describe the expert knowledge with grey uncertainty.
\end{abstract}

Keywords-ontology; grey number; knowledge representation; expert knownledge

\section{INTRODUCTION}

Ontology is widely used in knowledge engineering, software reuse, information retrieval and heterogeneous information processing[1]. With the help of ontology, human and computer can keep information exchange and integration, but the classical ontology is not able to handle the knowledge in many application domains with imprecise information, thus many researchers provided ontology extensions, such as probabilistic ontology[2] and fuzzy ontology[3].

In particular, fuzzy ontology is based on classical ontology and fuzzy mathematics, and many researchers have carried on the discussion and research on fuzzy ontology, to solve the problem of processing the fuzzy information in many fields. Calegari constructed a framework of fuzzy ontology with fuzzy description logic and fuzzy OWL language[4]. Pérez proposed a new linguistic extension of a consensus model to deal with the psychology of negotiation by using fuzzy ontology for improving group decision more precise and realistic[5].

However, due to limitation of human cognitive ability, there is also a kind of uncertainty, namely grey uncertainty and Prof. Deng proposed the theory of grey system in 1982[6]. Different from the the traditional statistics method, grey system is capable of handling grey uncertain information.

Since the grey system theory was proposed, many researchers carried out different researches on the application of related theory. Luo proposed the grey target decision method of relative bull's-eye distance, avoiding the uncertainty of index weight which affects the basic result[7]. Song defined the comprehensive off-target distance and established a model of goal programming[8].Liu Sifeng and his research team members also studied on the theory and application of grey system[9].
To our knowledge, no one has applied integrated grey system theory and ontology in expert knowledge representation. In this paper, we proposed grey ontology gOnto to represent expert knowledge with grey uncertain, which can also describe classical ontology and fuzzy ontology.

\section{GREY SYSTEMS THEORY}

\section{A. Preliminaries}

This section describes the basics about grey systems theory and uncertainty theory in order to understand the proposed model. Table I shows the comparison between grey systems theory, probability theory, and fuzzy theory[10].

In grey system theory, white refers to the information completely explicit, black refers to the lack of information, and grey information is incomplete. The incomplete information system is a grey system. Expert knowledge includes determined information and also dynamic unknown or incomplete information, as shown in Fig. I. Therefore, the two critical values are given to describe the scope of the unknown part, which is between the two critical values. Such information is described with interval grey number.

TABLE I. COMPARISON OF THEORIES

\begin{tabular}{|l|c|c|c|}
\hline \multirow{2}{*}{} & \multicolumn{3}{|c|}{ Theory } \\
\cline { 2 - 4 } & Grey systems theory & Probability theory & Fuzzy theory \\
\hline $\begin{array}{l}\text { Research } \\
\text { objects }\end{array}$ & $\begin{array}{c}\text { Small sample } \\
\text { uncertainty }\end{array}$ & $\begin{array}{c}\text { Large sample } \\
\text { uncertainty }\end{array}$ & $\begin{array}{c}\text { Cognitive } \\
\text { uncertainty }\end{array}$ \\
\hline Foundation & $\begin{array}{c}\text { Information } \\
\text { coverage }\end{array}$ & $\begin{array}{c}\text { Probability } \\
\text { distribution }\end{array}$ & Fuzzy sets \\
\hline Requirement & Few data points & $\begin{array}{c}\text { Large number of } \\
\text { data points }\end{array}$ & $\begin{array}{c}\text { Experts } \\
\text { knowledge }\end{array}$ \\
\hline $\begin{array}{l}\text { Data } \\
\text { requirement }\end{array}$ & Any distribution & $\begin{array}{c}\text { Probability } \\
\text { distribution }\end{array}$ & $\begin{array}{c}\text { Known } \\
\text { membership }\end{array}$ \\
\hline Objective & Laws of reality & Laws of statistics & $\begin{array}{c}\text { Cognitive } \\
\text { expression }\end{array}$ \\
\hline
\end{tabular}

Grey system theory is different from other interdisciplinary fields, and it has strong research significance, important and successful reality. Some questions are difficult to directly use fuzzy mathematics or probability theory to deal with. Fuzzy mathematics is mainly through the experience of cognitive processing uncertainty membership degree, and meanwhile probability theory needs mathematical statistics with sample size and distribution. 


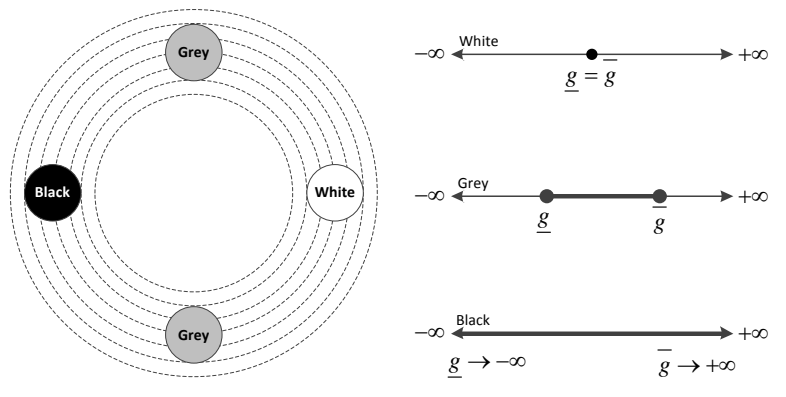

FIGURE I. GREY UNCERTAIN MODEL

In summary, classical ontology can only describe explicit concepts and relations, and fuzzy ontology can express explicit and fuzzy concepts and relations. Therefore, the uncertainty of expert knowledge is mainly grey uncertainty; ontology should be extended with grey system theory.

\section{B. Interval Grey Number and Its Calculation}

Grey number is the number that we only know its range but don't know its exact value. In practical application, grey number is indicated the number in a certain interval, which can describe the problem of grey uncertainty, but probability theory and fuzzy theory cannot handle [11]. Interval grey number is used to indicate grey number in interval.

Interval grey number can be expressed as $\otimes G\left[G^{l}, G^{\mathrm{u}}\right]$, , which $\mathrm{G}^{\mathrm{l}}$ is the lower bound of its range, $\mathrm{G}^{\mathrm{u}}$ is the upper bound of the range. When $\mathrm{G}^{\mathrm{l}}, \mathrm{G}^{\mathrm{u}}$ become a "definited number" or "the number of white". According to the gray domain (domain value of grey number) grey number can be divided into three kinds:

(1) grey number with only the upper bound

Gray domain is the gray number with determined upper bound and lower bound as $-\infty$, namely $\otimes \mathrm{G} \in[-\infty, \mathrm{a}]$, where a $\in \mathrm{R}$. For example, the machine tool can work in the humidity below $80 \%$, and this humidity is the grey number with only the upper bound.

\section{(2) grey number with only the lower bound}

Gray domain is the gray number with determined lower bound and upper bound as $+\infty$, namely $\otimes \mathrm{G} \in[\mathrm{a},+\infty]$, where a $\in \mathrm{R}$. For example, when we check the USB connectivity, and the fault connection time is greater than 10 milliseconds, so the fault connection time is the grey number with only the lower bound.

\section{(3) grey number with lower and upper bound}

Gray domain is the gray number with determined lower bound and upper bound, namely $\otimes \mathrm{G} \in[\mathrm{a}, \mathrm{b}]$, where $\mathrm{a} \in \mathrm{R}$ and $\mathrm{b} \in \mathrm{R}$. For example, the machine tool can work between temperature $0{ }^{\circ} \mathrm{C}$ and $55^{\circ} \mathrm{C}$, and the temperature is the grey number with lower and upper bound.

\section{GREY ONTOLOGY}

\section{A. Ontology And Description Logic}

In the field of knowledge engineering, various objects and their relationship of the knowledge should be processed, and should be allowed to transfer between different subjects, such as a person, computer, software. Ontology can provide a structured language, clear definitions of the relationships between different concepts and concept, and is fit for the essential communication between different subject areas.

The theoretical foundation of ontology is description logic (DL). DL based knowledge representation system contains a knowledge base and reasoning mechanism, and the knowledge base is composed of ABox and TBox as shown in Fig. II.

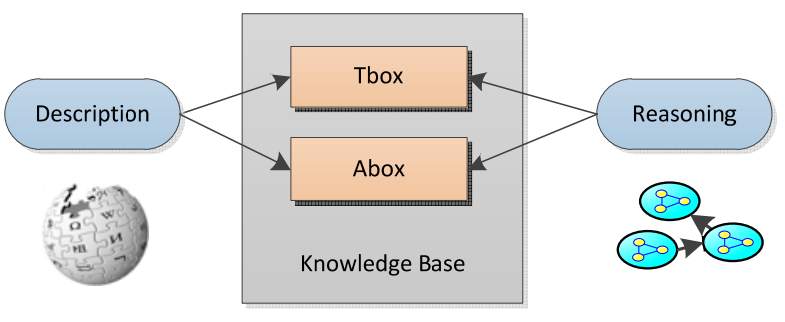

FIGURE II. DESCRIPTION LOGIC AND KNOWLEDGE BASE

TBox contains the connotation of knowledge in the field, usually in terms of axioms (Terminological axioms) to describe concepts. Normally axioms have two main forms: inclusion and equality.

Inclusion: $\mathrm{c} \sqsubseteq \mathrm{d}(\mathrm{r} \sqsubseteq \mathrm{s})$, such as $\mathrm{CNC}$ Lathe $\sqsubseteq \mathrm{CNC}$ Machine Tool

Equality: $\mathrm{c} \equiv \mathrm{d}(\mathrm{r} \equiv \mathrm{s})$, such as $\mathrm{CNC}$ Lathe $\equiv$ Lathe $\Pi$ $\mathrm{CNC}$

where $\mathrm{c}$ and $\mathrm{d}$ are concepts, and $\mathrm{r}$ and $\mathrm{s}$ are relations.

\section{B. The Model of Grey Ontology and Its Definition}

Classical ontology and the fuzzy ontology have the limitation to describe grey uncertainty, but in the expression of expert knowledge, many contents belong to the category of grey theory. In order to describe the grey uncertainty, grey ontology is proposed in this paper, meanwhile grey concept and grey relation are also introduced.

Definition 1: Ontology with properties and relationships of grey uncertainty is grey ontology. (Grey Ontology, for short gOnto), Grey Ontology is quadruple $\mathrm{GO}=\left(\mathrm{C}, \mathrm{R}_{\otimes}, \mathrm{A}_{\otimes}, \mathrm{I}\right)$, then

(1)C represents the set of class, and each element is the class with standardized description.

$(2) \mathrm{R}_{\circledast}$ is the set of grey relationships, any grey relationship $\mathrm{r}_{\otimes} \in \mathrm{R}_{\otimes}$ is with triple structure $\mathrm{r}_{\otimes}\left(\mathrm{c}_{1}, \mathrm{c}_{2}, \otimes\right)$, and $\mathrm{c}_{1}, \mathrm{c}_{2} \in \mathrm{C}$ are classes, $\otimes$ represents the relationship strength.

$(3) \mathrm{A}_{\circledast}$ is the set of grey attributes, any grey attribute $\mathrm{a}_{\otimes} \in$ $\mathrm{A}_{\otimes}$ is with quadruple structure $\mathrm{a} \otimes(\mathrm{c}, \mathrm{t}, \mathrm{u}, \otimes)$, and $\mathrm{c} \in \mathrm{C}$ is class, 
$\mathrm{t}$ represents attribute type, $\mathrm{u}$ represents attribute unit, $\otimes$ represents the attribute value.

(4)I represents the set of individuals.

It should be pointed out that the definition of the grey ontology involves the grey attribute and the grey relation, and if any of them belongs to grey category, it is considered that the ontology is grey ontology.

\section{Main Element S of Grey Ontology}

The main difference between grey ontology and other ontologies is that grey ontology is able to describe the grey uncertainty, including the grey relation and the grey attribute, and the grey ontology model is shown in Fig.III.

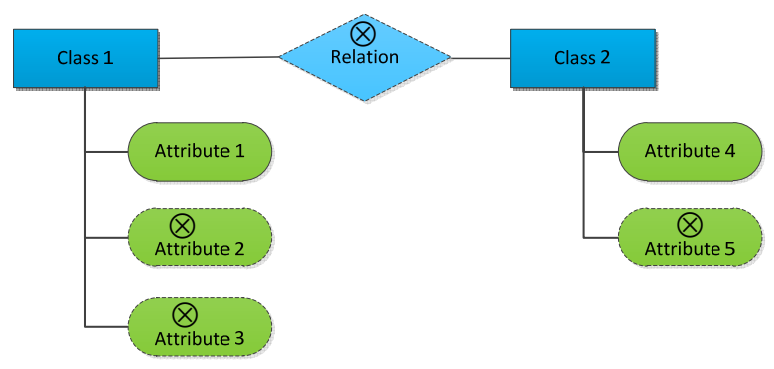

FIGURE III. GREY ONTOLOGY MODEL

\section{(1)Grey Relation $\mathrm{R}_{\circledast}$}

The difference between grey relation with explicit and fuzzy relation are described as following:

Definition 2: $c_{1}$ and $c_{2}$ are two sets in the domain, $r_{e}$ is the explicit relationship of them, then

$$
r_{\mathrm{e}}=1 \text { or } r_{\mathrm{e}}=0
$$

where $r_{e}=1$ represent $c_{1}$ and $c_{2}$ with some relationship; $r_{e}=0$ represent $\mathrm{c}_{1}$ and $\mathrm{c}_{2}$ have no relationship.

Definition 3: $c_{1}$ and $c_{2}$ are two sets in the domain, $r_{f}$ is the fuzzy relationship of them, then

$$
\mathrm{r}_{\mathrm{f}}: \mathrm{c}_{1} \times \mathrm{c}_{2} \rightarrow[0,1]
$$

where $c_{1}$ and $c_{2}$ have fuzzy relationship and their relationship strength $r_{\mathrm{f}}$ is between 0 and 1 .

Definition 4: $c_{1}$ and $c_{2}$ are two sets in the domain, $r_{\otimes}$ is the grey relationship of them, then

$$
\mathrm{r}_{\otimes}: \mathrm{c}_{1} \times \mathrm{c}_{2}=\otimes
$$

where $\otimes$ is an interval grey number.

\section{(2)Grey Attribute $A_{\circledast}$}

The difference between grey relation with explicit and fuzzy relation are described as following:
Definition 5: $\mathrm{c}$ is one set in the domain, $\mathrm{a}_{\mathrm{e}}=\partial$ is the explicit attribute of $\mathrm{c}$, then

$$
\left(a_{e} \rightarrow c\right): \partial
$$

where $\partial$ is the explicit attribute value of $\mathrm{c}$.

Definition 6: $c$ is one set in the domain, $a_{\mathrm{f}}=[a, b]$ is the fuzzy attribute of $\mathrm{c}$, then

$$
\left(\mathrm{a}_{\mathrm{f}} \rightarrow \mathrm{c}\right):[\mathrm{a}, \mathrm{b}]
$$

where $[a, b]$ is the fuzzy attribute value of $c$.

Definition 7: $\mathrm{c}$ is one set in the domain, $\mathrm{a} \otimes$ is the grey attribute of $\mathrm{c}$, then

$$
\left(\mathrm{a}_{\otimes} \rightarrow \mathrm{c}\right): \otimes
$$

where $\otimes$ is an interval grey number.

\section{REPRESENT ABILITY AND DESCRIBE LANGUAGE OF GREY ONTOLOGY}

\section{A. Represent Ability}

In this paper three types of ontology are mentioned, classical ontology, fuzzy ontology and grey ontology. Classical ontology is the explicit representation and fuzzy ontology is used to represent fuzzy knowledge. Grey ontology is a uniform of classical ontology and fuzzy ontology, and these two ontologies can be described by the grey ontology, as shown in Fig. IV.

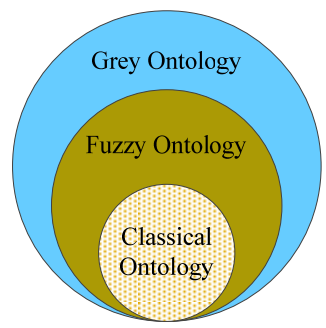

\section{FIGURE IV. REPRESENT ABILITY OF GREY ONTOLOGY}

Because grey uncertainty is widespread, grey ontology gOnto has a wide range of application scenarios. For example, in enterprise resource management, due to production is a very complex social activities, it is full of grey uncertainty. In fault diagnosis field, due to limitation information-obtain capabilities, human will make inaccurate judgments.

\section{B. Describe Language}

In order to describe the grey ontology using OWL which is the most popular language for ontology, and without change the existing semantics and syntax of the OWL, g-OWL is 
proposed as an extension of standard OWL. The key way of gOWL to describe grey uncertainty is described as flowing.

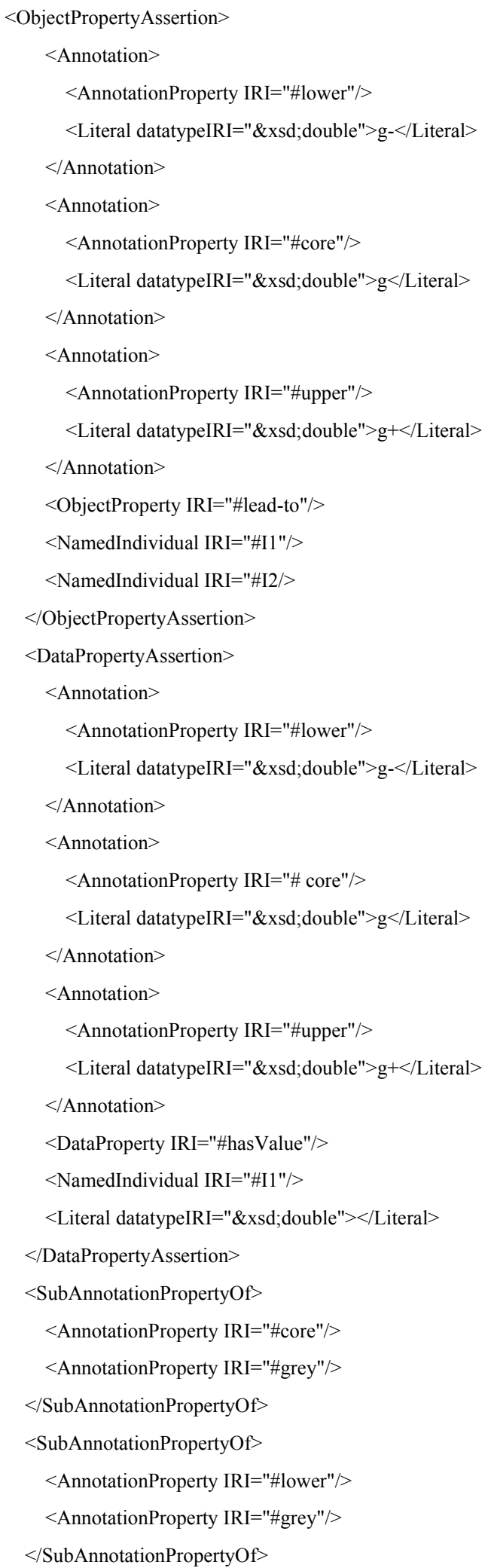

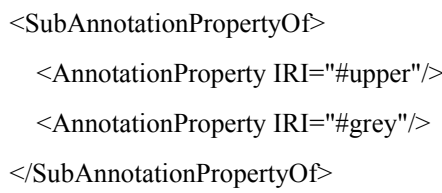

\section{CONCLUSION}

Expert knowledge representation with ontology is a popular research topic. This paper proposed grey ontology to handle grey uncertainty. Based on grey systems theory, the interval grey number and its calculation are introduced. Grey ontology is proposed and the main elements are also analyzed.

After that represent ability and applications of grey ontology are introduced. And the standard ontology language OWL is also extended as g-OWL to describe the grey uncertainty. It shows that grey ontology can overcome the limitation of other ontologies to describe the expert knowledge with grey uncertainty.

\section{ACKNOWLEDGMENT}

Project supported by the project "Siemens Automation Cooperates with Education". The authors are grateful to the machine tool service engineers who provided a lot of work with their experience.

\section{REFERENCES}

[1] I. B. Arpinar, A. Sheth, C. Ramakrishnan, et al. Geospatial Ontology Development and Semantic Analytics[J]. Neuroscience Letters, 2005, 383(3):225-230

[2] F. Ongenae, M. Claeys, T. Dupont, et al. A probabilistic ontology-based platform for self-learning context-aware healthcare applications[J]. Expert Systems with Applications, 2013, 40(18):7629-7646.

[3] F. Bobillo, U. Straccia. Fuzzy ontology representation using OWL 2[J]. International Journal of Approximate Reasoning, 2011, 52(7):1073-1094.

[4] S. Calegari, D. E. Ciucci. Fuzzy Ontology, Fuzzy Description Logics and Fuzzy-OWL[J]. Lecture Notes in Computer Science, 2007:118-126.

[5] I. J. Pérez, R. Wikstrm, J. Mezei, et al. Linguistic Consensus Models Based on a Fuzzy Ontology[J]. Procedia Computer Science, 2013, 17:498-505.

[6] Julong Deng. Introduction to Grey system theory[J]. Journal of Grey System, 1989, 1(1):1-24.

[7] Dang Luo, Xia Wang. The multi-attribute grey target decision method for attribute value within three-parameter interval grey number[J]. Applied Mathematical Modelling, 2012, 36(5):1957-1963.

[8] Jie Song, Yaoguo Dang, Zhengxin Wang, et al. New decision model of grey target with both the positive clout and the negative clout[J]. Systems Engineering-Theory \& Practice, 2010, 9(8):1199-1217.

[9] Lifeng Wu, Sifeng Liu, Zhigeng Fang, et al. Properties of the $\operatorname{GM}(1,1)$ with fractional order accumulation[J]. Applied Mathematics \& Computation, 2015, 252:287-293.

[10] M. S. Memon, Y. H. Lee, S. I. Mari. Group multi-criteria supplier selection using combined grey systems theory and uncertainty theory[J]. Expert Systems with Applications, 2015, 42(21):7951-7959.

[11] Y. P. Cai, G. H. Huang, X. Wang, et al. An inexact programming approach for supporting ecologically sustainable water supply with the consideration of uncertain water demand by ecosystems[J]. Stochastic Environmental Research and Risk Assessment, 2011(25): 721-735. 